\title{
GIS-Based Spatial Analysis of Tai Place Names in Southern China: An Exploratory Study of Methodology
}

\author{
Fahui Wang ${ }^{1}$, John Hartmann², Wei Luo ${ }^{1}$, Pingwen Huang ${ }^{3}$ \\ ${ }^{1}$ Department of Geography, Northern Illinois University, DeKalb, IL 60115-2854, USA \\ E-mail: fwang@niu.edu \\ ${ }^{2}$ Department of Foreign Languages and Literatures, Northern Illinois University \\ ${ }^{3}$ Guangxi University for Nationalities, Nanning, China
}

\begin{abstract}
This research is part of an ongoing larger project dealing with the historical origins of the Tai in southern China and Southeast Asia. The sinification of ethnic minorities, such as the Tai, has been a long and ongoing historical process in China. One indication of historical change is reflected in geographical place names over time. Many older Tai names can be recognized because they are named after geographical or other physical features in Tai, such as "rice field”, "village”, "mouth of a river”, "mountain”, "basin”, etc. On the other hand, many other older Tai place names have been obliterated or modified in the process of sinification. The objective of the larger project is to reconstruct the historical past settlements of the Tai from place names. This research is an exploratory study demonstrating how modern GIS and spatial analysis techniques can benefit researchers in historical-linguistic-cultural studies who have been less exposed to them. In particular, GIS-based spatial interpolation and clustering methods are used to map the spatial patterns and identify the concentrations of Tai place names; GIS overlays are used to define some spatial variables, which are then fed into a logistic regression in attempt to explain the spatial patterns.
\end{abstract}

Keywords

place names, spatial analysis, Tai, sinification

\section{INTRODUCTION}

The Tai are surely one of the "successful" societies as described by Jared Diamond (1997) in his classic, Guns, Germs, and Steel. The irrigated rice agriculture they refined in southern China some 2000 years ago enabled them to expand far beyond their geographic origins and project their economic and political influence to much of mainland Southeast Asia. Many toponyms, especially at the village level are evidence of their expansion. The majority of toponyms are derived from identifiable features of both the natural and manmade landscape: water sources, landforms and bioforms; rice fields and passageways. An environmental record and indigenous knowledge system has thus been preserved in toponyms. Some of the earlier Tai place names-and the cultural, linguistic and human history they encapsulate-have, however, been obscured by time, political change, and the work of map makers, most notably in China.

The objective of a larger ongoing project is to reconstruct the historical past settlements of the Tai from place names. That project covers the entire Tai language domain including southern China (Guizhou, Yunnan, Guangxi, Guangdong and Hainan) and Southeast Asia (northern Vietnam, Laos, and Thailand). The exploratory research we are reporting on in this article uses a small study area (i.e., Qingzhou Prefecture in Guangxi Autonomous Region in southern China) covering just one year (1979) in order to test most of the analytical methods that will be used in the larger project. See Figure 1 for the location of study area. In particular, this study shows how modern GIS and spatial analysis techniques can benefit researchers in historical-linguistic-cultural studies who have been less exposed to GIS.

The remainder of this paper is organized as follows. The next section provides some background information for Tai toponymical analysis, followed by a section discussing the study area and data sources. The research methods and results are presented in two sections: one on GIS-based modeling of spatial patterns and one on validation and explanation by regression analysis. The paper is concluded with a brief summary.

\section{BACKGROUND: TOPONYMICAL ANALYSIS}

For years anthropologists and historians have written papers on the topic of “Who Are the Tai?” (e.g., O’Connor, 2000). They attempt to draw up a set of traits that set the Tai apart from other peoples. Our outlook has been that "being Tai" is a cultural construct centering around the emergence of irrigated rice technology in southern China that came to be dominated and spread by genetically diverse peoples who shared a basic agrarian vocabulary and naming tradition that linguists identify as Tai (Hartmann, 1998). The family of Tai languages has a broad geographic spread. In its totality, it stretches from the island of Hainan, through much of the north of Vietnam and areas of southern China (chiefly Guangxi, Guizhou and Yunnan, and part of Guangdong), through Laos and Thailand, across the northern reaches of Burma and finally into Assam in India. The history of the Tai is one of peasants colonizing new lands

1082-4006/06/1201-01\$5.00

(C)2006 The International Association of Chinese Professionals in Geographic Information Science (CPGIS) 
using waterways for transport, irrigation, and ritual and the clearing of myriad muang (geographical "basins" in proto-Tai speech) that, in turn, became petty kingdoms, and in two instances modern nation states: Muang Thai (Thailand) and Muang Lao (Laos).

Comparative-historical linguistics has shown with considerable certainty that the Tai originated in the border areas between southern China and northern Vietnam. Our prior research (Luo, et al., 2000) indicates that the infusion of Han people into Zhuang Tai and other Tai-related groups has led to some areas of absorption or replacement by succeeding waves of Han migrations. For instance, in the $13^{\text {th }}$ century, the Mongols conquered all of China and pushed Han south by entering Guangdong and its neighboring region Guangxi, mostly through the Meiling Pass (see the location in Figure 1). There has even been incursion into the less accessible western corner of Guangxi causing yet further Tai movement to the west and south as a result. This process of sinification, to some extent, is recorded in the change of place names. By identifying whether a place is a Tai name and mapping the extent of Tai place names, we hope to approximate the settlement range of Tai in the past.

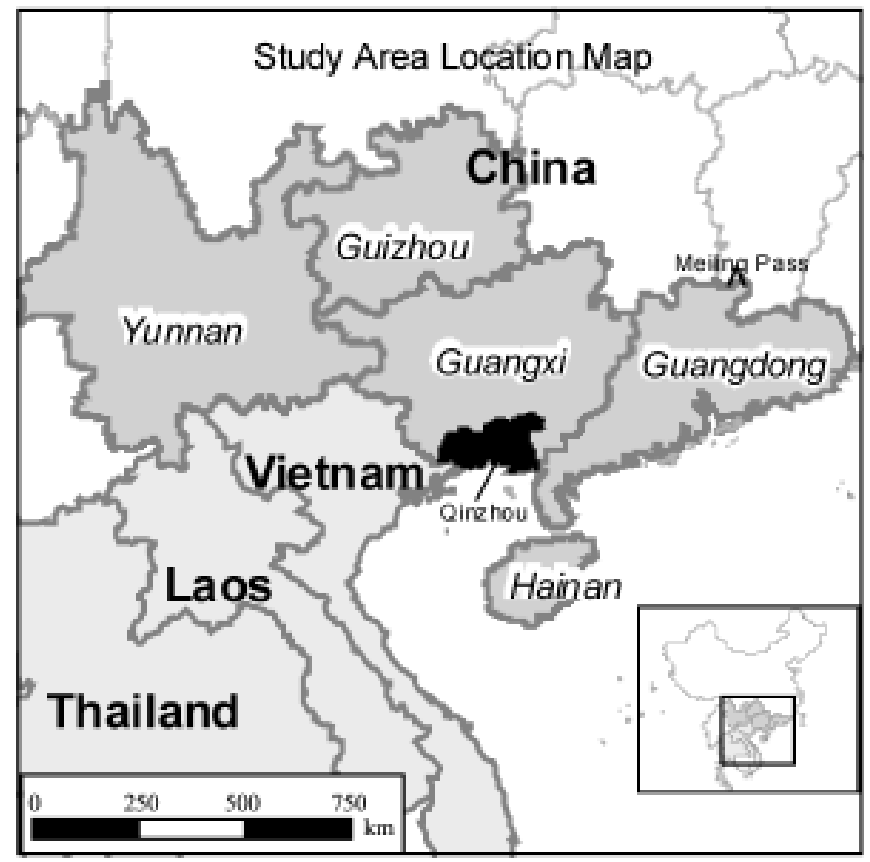

Figure 1. The study area

There have been a good number of Tai toponymical studies in the recent literature. For example, Pranee Kullavanijaya (1996: 120-134) compared place names in seven Tai Zhuang counties in Guangxi Autonomous Region with four provinces in northeastern Thailand, and pointed out that village names may reveal the history, migration, and contact with other ethnic groups. Using place name data from Thai government documents, Sujritalak Deepadung (1998) discovered five major semantic categories for names and found that "the village names to the western region of Thailand rely significantly on physical geography of the area" including 30 morphemes used for references to water (rapids, bend of a watercourse, ditch, tributary branch of a river, the waters, canal, muddy place, fountain, spring, waterfall, sea, waterway, swamp, and so on). Kaluzyñska (2002) studied the modern Chinese place names (counties and cities) including Tai. Zhuang et al. (1988) reported the result from a large research team on Tai place names in Guangxi. Wu (1988) examined how the Bouyei (a Tai-related group) place names in Guizhou are related to the rice planting culture.

On a very basic level, especially the village level, which is the level that the Tai were confined to for most of their history, names were based on identifiable features of the landscape, both natural and manmade. However, many Tai place names have been transliterated to their nearest Chinese-sounding names by Han officials and historians. Thus the Tai Lue prefecture Sipsongpanna ("Twelve Thousand Rice Fields") was transliterated in Chinese as Xishuangbanna (西双版纳), completely obliterating the original Dai meaning and historical significance of the name. In other cases the system of qieyun 切 韵 has been employed in which two Chinese characters are used to render a single syllable of the indigenous language. Many older Tai names have been concealed and require considerable sleuthing by linguists and historians working in concert.

Toponymical analysis in this pilot project begins with Tai place names as purely linguistic forms and analyzed in terms of phonology, grammar (headwords and modifiers) and historical changes in both, employing the methods of comparativehistorical linguistics. For example, place names containing 纳/ 那(na), 板(ban) etc in Chinese are most likely Tai. Place names are not just linguistic forms but also cultural and societal artifacts. Rigorous toponymical analysis is a time-consuming process combining fieldwork, gazetteer and consultation with local historians. Fortunately, for studies in China, there is rich information of place names in local gazetteers, compiled and updated regularly by an office of place names in each provincial and county government. Such gazetteers describe place names of administrative regions and natural and manmade features of the landscape. If a place is named by a minority nationality (ethnic group) instead of Han, it explains the meaning in Chinese. Figure 2 shows a sample entry of a county name in Yunnan Provincial Gazetteer (Yunnan Placename Editorial Committee, 1997). It clearly describes the history of the place name and its origin (in this case, Yimen County was named in Song Dynasty after a spring by $\mathrm{Yi}$, an ethnic group speaking a dialect of Tai).

\section{STUDY AREA AND DATA SOURCE}

For demonstrating the GIS research methodology, we select Qinzhou Prefecture, Guangxi Autonomous Region in a 1979 map as a pilot study area (see Figure 1 for location). The area is settled by Han and Tai-speaking minority ethnic groups and provides a good testing site to examine the contrast between Tai and non-Tai place names. In addition, some members of the research team are already knowledgeable in 
易门县【Yìmén Xiàn】处北纬 $24^{\circ} 40^{\prime}$ 、东经 $102^{\circ} 09^{\prime}$, 位于玉溪地区北部。面积1 571 平方公里。人口 16.1 万, 有率、哈尼、回、苗等少数民族 4.6 万人。辖龙泉、六街、绿 计 3 镇及 5 乡 (含 3 率族乡)。县政府驻龙泉镇。汉为益州郡双柏县地, 三国属建宁郡, 东晋、南朝属晋宁郡。唐代设唐封县, 属钧州, 南诏属拓东节度。尔大理名沸源, 属陆 阐府。蒙古至元四年（1267）设 淒门千户, 属巨桥万户府, 元至元十二年（1275）设易 门县, 属中庆路昆阳州。明、清属云南府昆阳州。1914 年属滇中道, 1916 年直属省。1950 年属玉溪专区, 1958 年改易门矿区, 1959 年复名易门县, 1970 年属玉溪地区。因水得名, 城西有泉, 無语名洟源, 坝子称洟门, 后讹为 “易门”。处滇中湖盆高原与滇中红层高原 交界地带。西部多山, 绿汁江沿西界南流, 扒河纵贯东部, 南流后向西汇入绿汁江。有 丰富的铜铁矿。有安双、易岟、杨三等公路、风景胜地有大龙泉。

Figure 2. A sample entry of place name in gazetteers

that area. The 1979 map is chosen as it is the only map with village names available to us for the study area.

The linguists on the team have identified and separated the Tai place names from the non-Tai place names based on the toponymical analysis techniques as explained in the previous section. The classification is based our preliminary research on available resources. Future research will employ a more rigorous approach by combining fieldwork, gazetteer and consultation with local historians. The study area has a total of 568 place names, among which 106 are identified as Tai place names. Figure 3 shows the distribution of Tai and nonTai place names, from which we can vaguely see areas with more representations of Tai place names and other with less. In order to test whether the spatial pattern of Tai place names is consistent with the Tai population distribution, we also need the population data of different ethnic groups in the study area. Dr. Shuming Bao at the China Data Center of the University of Michigan provided us the 2000 census data for the study area at the township (xiang/zhen 乡镇) level. There are 103 townships in the study area. While there is a 21-year gap between the data of place names (1979) and census data (2000), there have been only minimal changes in place names during this time period.

For analyzing the relationship between physical environments and place names, GIS data on elevations are obtained from the USGS's GTOPO30 global digital elevation model (DEM) dataset (http://edcdaac.usgs.gov/gtopo30/gtopo30.asp) with a spatial resolution of $1 \mathrm{~km}$. This is sufficient for examining the effect of topography on overall Tai settlement patterns. Place names can be also related to the settlement and migration

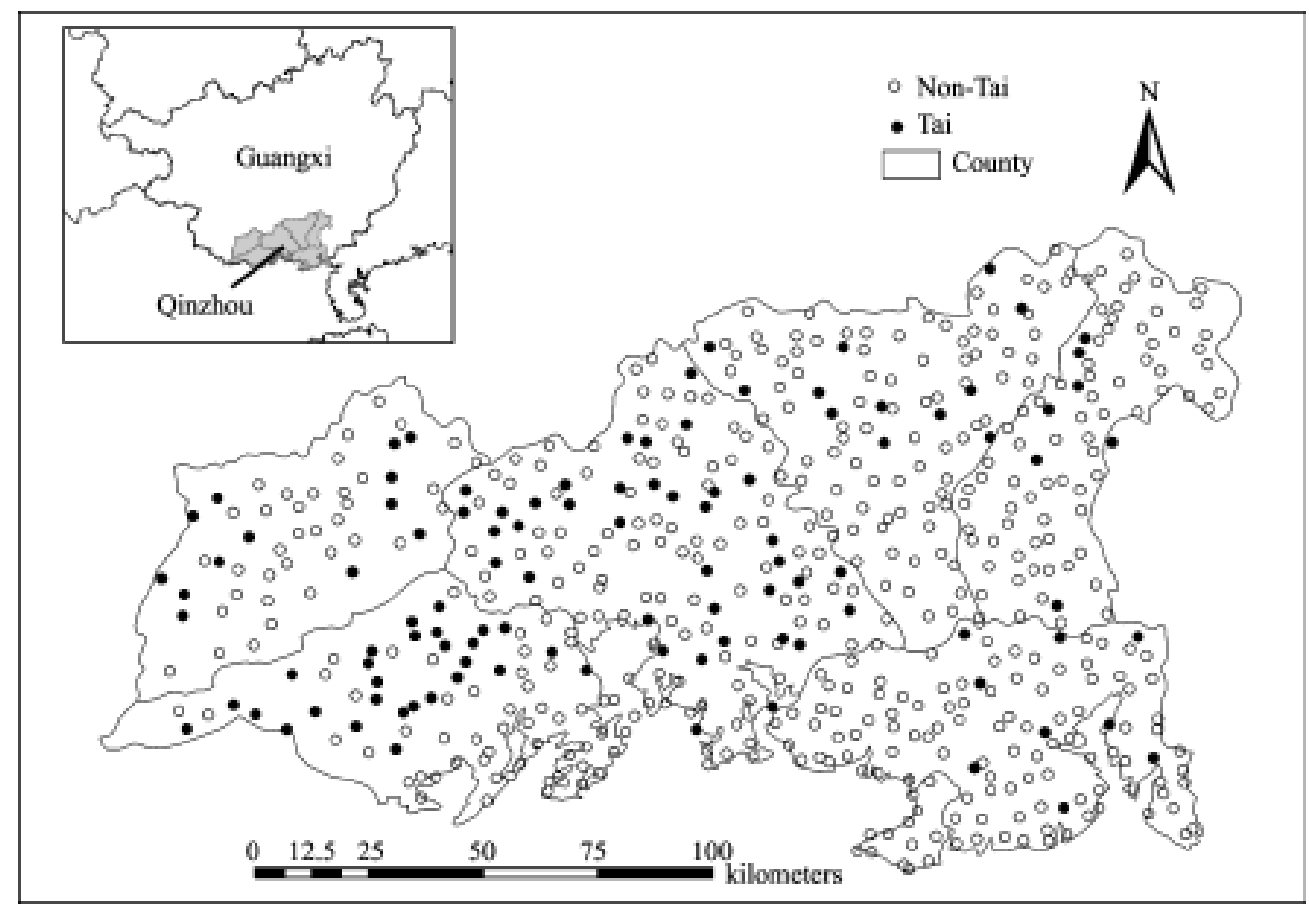

Figure 3. Tai and non-tai place names in Qinzhou (1979) 
patterns of different Tai groups, who have followed both water and land pathways and trade routes. GIS layers of major transportation routes are collected by a member of the research team for other research projects.

\section{MODELING SPATIAL PATTERNS IN GIS}

A Geographic Information System (GIS) is a computer system for capturing, storing, querying, analyzing, and displaying geographically referenced data. Mapping is a fundamental function of GIS. However, only limited information can be extracted by visually examining maps that simply show the distribution of Tai place names as in Figure 3. Spatial modeling techniques help better visualize the spatial pattern and advance the analysis.

\section{A. Spatial Smoothing}

The classification of place names in the study area is first coded in GIS as a binary variable identifying whether a place name is Tai $(=1)$ or non-Tai $(=0)$. A common spatial smoothing technique, i.e., the floating catchment area (FCA) method, is then used to examine the spatial concentrations of Tai place names. Like moving averages that are calculated over a longer time interval (e.g., five-day moving average temperatures), the FCA method draws a circle or a square around a location to define a filtering window, and uses the average value (or density of events) within the window to represent the value at the location. In this case, a circle (e.g., with a $10-\mathrm{km}$ radius) is drawn around each place, the ratio of Tai place names to all place names within the circle (hereafter referred to as "Tai place ratio") is computed. The circle moves from one place to another until the ratios are obtained for all places. Each ratio represents the concentration of Tai place names around a place. A larger circle (i.e., a larger filtering window) leads to stronger spatial smoothing, and thus better reveals regional than local patterns; and a smaller circle corresponds to reverse effects (Fotheringham, et al., 2000: 46).

By doing so, the original discrete variable of Tai place names ( 0 or 1 ) is converted into a continuous ratio variable (any numerical value ranging from 0 to 1 ). A map of the Tai place ratios in Figure 4 shows the gradual change from places with higher Tai place ratios (mainly in the west) to places with lower ratios (in the east) continuously. Different window sizes may be experimented. In our case, a window of a $10-\mathrm{km}$ radius yields an adequate degree of smoothing while generating reasonable variability.

\section{B. Trend Surface Modeling}

Figure 4 shows some improvement over Figure 3 in displaying the spatial variation of Tai place name concentrations. However, both are still point-based (i.e., Tai place ratios are known only at locations with available place names), and the spatial trend across the whole study area is not clear. Spatial interpolation uses known values at given locations to estimate unknown values at other locations, and generates a continuous surface for the whole study area. One commonly-used spatial interpolation method is trend surface modeling.

Trend surface modeling uses a polynomial equation of $x-y$ coordinates to approximate points with known values such as

$$
z=f(x, y)
$$

where the attribute value $z$ is considered as a function of $x$ and $y$ coordinates (Bailey and Gatrell, 1995). For example, a cubic trend surface model is written as

$z(x, y)=b_{0}+b_{1} x+b_{2} y+b_{3} x^{2}+b_{4} x y+b_{5} y^{2}+b_{6} x^{3}+b_{7} x^{2} y+b_{8} x y^{2}+b_{9} y^{3}$

The equation is usually estimated by an ordinary least square

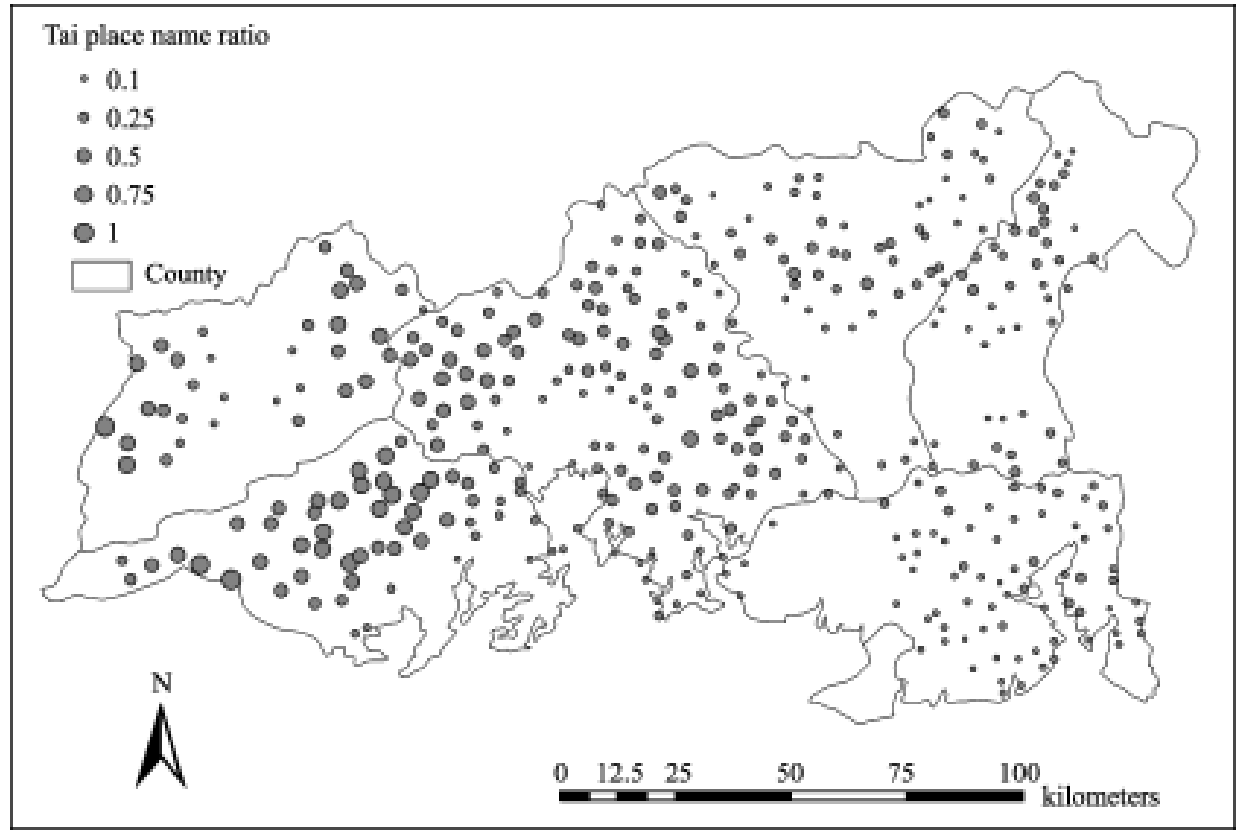

Figure 4. Tai place name ratios(10-km radius) in Qinzhou 
regression. The estimated polynomial is then used to project unknown values at any locations. Higher-order models are needed to capture more complex surfaces and yield lower $\mathrm{RMS}^{1}$.

Figure 5 shows the trend surface using a 10th-order polynomial based on the Tai place ratios ${ }^{2}$. It clearly shows the highest concentration of Tai place names in the southwest corner that stretches towards the north in one case and in the other case towards northeast, in a reverse "U-shape". Two other concentrations of Tai place names are minor: one in the very west and another in the north.

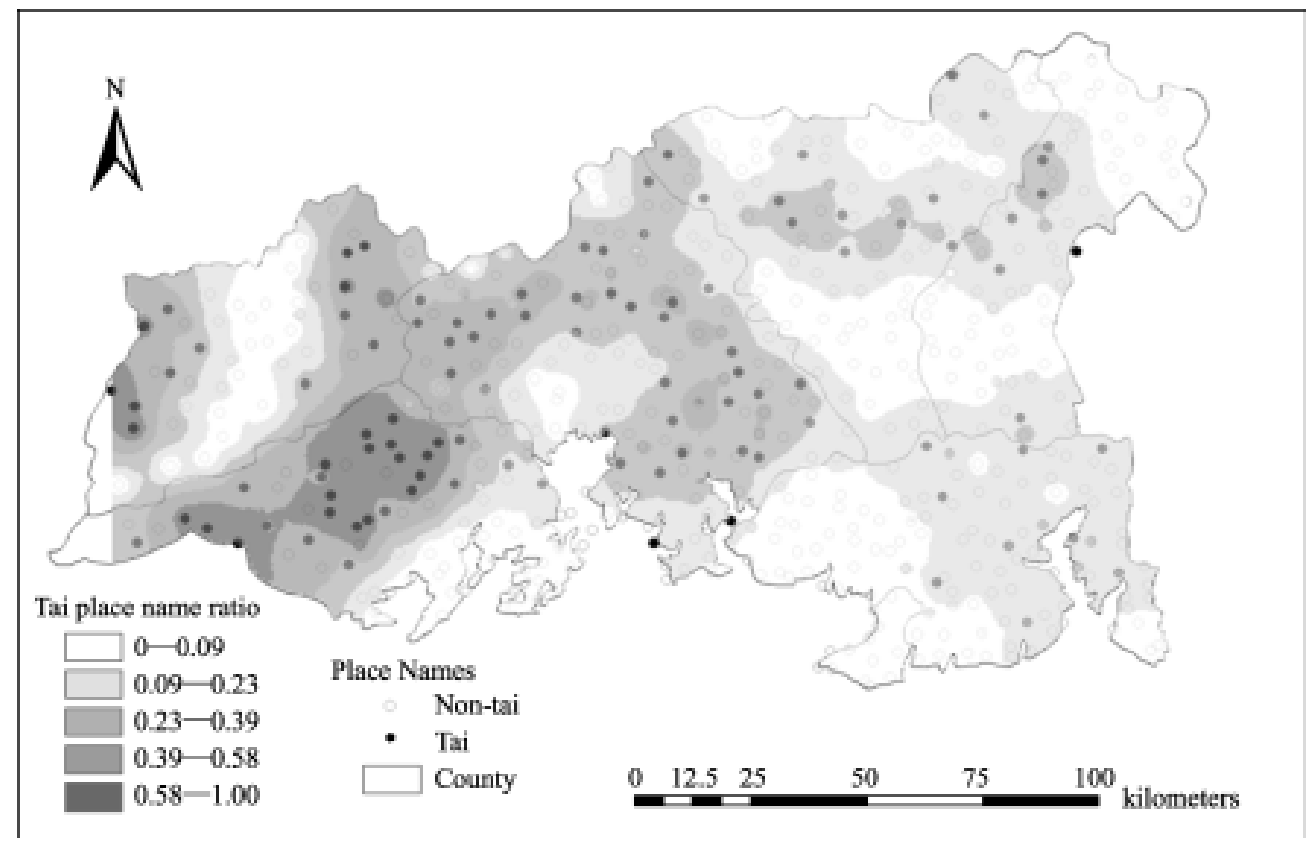

Figure 5. Trend surface modeling of Tai place names in Qinzhou

\section{Spatial Cluster Analysis}

Both spatial smoothing and trend surface modeling are useful for mapping the Tai place names. However, both are merely descriptive. Even randomly distributed events may appear to exhibit some local pockets of concentration. In other words, elevated Tai place ratios in some areas might arise simply by chance alone. The pattern generally warrants study only when it is statistically significant (Jacquez, 1998). Are the occurrences of Tai place names in some areas significantly more frequent than other areas? The answer relies on rigorous statistical analysis - spatial cluster analysis. Spatial cluster analysis has been most widely used in health-related studies to detect clusters of diseases among healthy individuals.

One method detecting spatial clusters of point data is the spatial scan statistic or SaTScan developed by Martin Kulldorff

${ }^{1}$ RMS (root mean square) measures the goodness of fit such as $R M S=$ $\sqrt{\sum_{i=1}^{n}\left(z_{i, o b s}-z_{i, e s t}\right)^{2} / n}$, where $z_{i, o b s}$ is the observed value at location $i$, $z_{i, e s t}$ is the estimated value at location $i$, and $n$ is the total number of points.

${ }^{2}$ Figure 5 is based on a global trend surface model that utilizes all control points with known values to estimate an unknown value (i.e., one polynomial function for the whole study area). A local trend surface model uses a sample of control points to estimate an unknown value (i.e., the polynomial function varies from place to place). One may also use the original binary variable Tai (= 0 or 1$)$ as the dependent variable in a logistic trend surface model to generate a probability surface. (http://www.satscan.org). SaTScan uses a circular window to scan the entire study region, and the radius of the window varies continuously in size from 0 to 50 percent of the total observations. In our case, a non-Tai place name serves as "control" (coded as 0), and a Tai place name is "case" (coded as 1). For each circle, the method computes the likelihood that the occurrence of case is higher inside the window compared to outside the window. A Bernoulli model is used to assess statistical significance. Under the Bernoulli model, the likelihood function for a specific window $z$ is

$$
L(z, p, q)=p^{n}(1-p)^{m-n} q^{N-n}(1-q)^{(M-m)-(N-n)}
$$

where $N$ is the total number of cases in the study region, $n$ is the number of cases in the window, $M$ is the total number of controls in the study region, $m$ is the number of controls in the window, (probability of being a case within the window), and $q=(M-m) /(N-n)$ (probability of being a case outside the window).

The likelihood function is maximized over all windows, and the "most likely" cluster is one that is least likely to have occurred by chance. The likelihood ratio for the window is reported and constitutes the maximum likelihood ratio test statistic. Its distribution under the null hypothesis and its corresponding $p$-value are determined by a Monte Carlo simulation approach. The method also detects secondary clusters with the highest likelihood function for a particular window that do not overlap with the most likely cluster or other secondary clusters. Figure 6 shows the primary and 


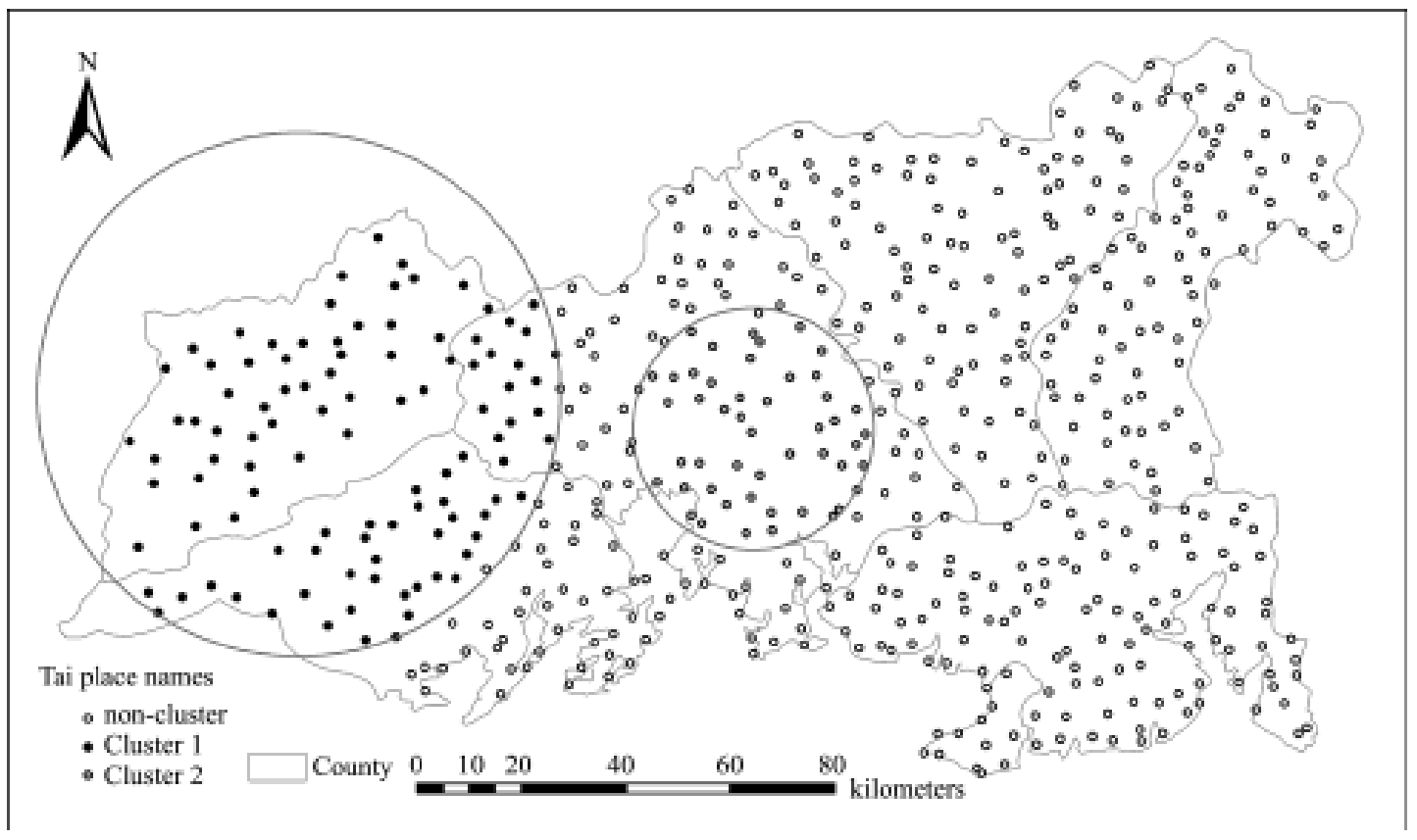

Figure 6. Clusters of Tai place names in Qinzhou

secondary clusters of Tai place names in the study area. The spatial cluster analysis confirms that the major concentration of Tai place names is in the west, and a minor concentration in the middle.

\section{VALIDATION AND EXPLANATION BY REGRESSION ANALYSIS}

\section{A. Spatial Pattern of Tai Place Names vs. Distribution of Tai Population}

One of the major objectives of the larger project is to reconstruct the historical Tai settlement pattern from the distribution of Tai place names. While the naming process may be related to many cultural, political, and historical factors, the underlying assumption is that a place named by Tai is where Tai have been present. One way to validate the assumption is to examine whether the distribution of Tai population is consistent with that of Tai place names.

Based on the 2000 Census of Population at the township level, Figure 7 shows the ratios of Tai population (including the ethnic groups of Zhuang, Dai, Bouyei and Yi), represented by symbols of different sizes across townships. The spatial variation of the Tai population ratio can also be modeled by trend surface interpolation, shown as the background in Figure 7. The highest Tai population ratios are observed in the northwest and decline towards east. The general trend is consistent with that in Figure 5. Both Figures show the higher Tai ratios in the west than in the east. However, in the west

\footnotetext{
${ }^{3}$ Note that the Tai place ratios are associated with the 568 place names (including villages) and the Tai population ratios are those of the 103 townships. To match the two, we used the interpolated Tai place ratio at the location of each township to represent the Tai place ratio there.
}

part, the Tai place ratios are higher in the south than the north (in Figure 5) whereas the Tai population ratios are higher in the north than in the south (in Figure 7).

Figure 8 plots the relationship between Tai population ratios versus Tai place name ratios in the study $\mathrm{area}^{3}$, and regression analysis is used to test whether the two are correlated with each other. A direct regression of Tai population ratios against Tai place name ratios yields $\mathrm{R}^{2}=0.198$, implying a correlation coefficient of 0.445 ; and a regression of Tai population ratios against the logarithms of Tai place name ratios (for adjustment of the scale) yields $\mathrm{R}^{2}=0.327$, implying a correlation coefficient of 0.572. While the correlation is not as evident as expected, the relationship is statistically significant in both cases. Many factors may have contributed to the not-so-strong correlation. The most important one is perhaps that a place name remains unchanged for an extended period of time and does not necessarily reflect the ethnicity or language of modern settlers. In other words, a place name may better represent the ethnic group that governed the area in the past instead of the present time.

\section{B. Explaining the Pattern of Tai Place Names}

Physical environments can play an important role in the settlement patterns we see today (e.g., Stanley and Chen, 1996). This is especially true for the Tai people, as they grow wet paddy rice, which requires ample supply of water and low lying flat areas (Husson, et al., 2001). Our previous study (Luo, et al., 2000) of linguistic terms related to wet rice farming demonstrated that the settlement patterns of Zhuang and Bouyei in the border areas of Guizhou and Guangxi are closely linked to the physical environments that are favorable for growing wet rice, i.e., they tend to concentrate at low and flat areas with good access to water. Place names can also be 


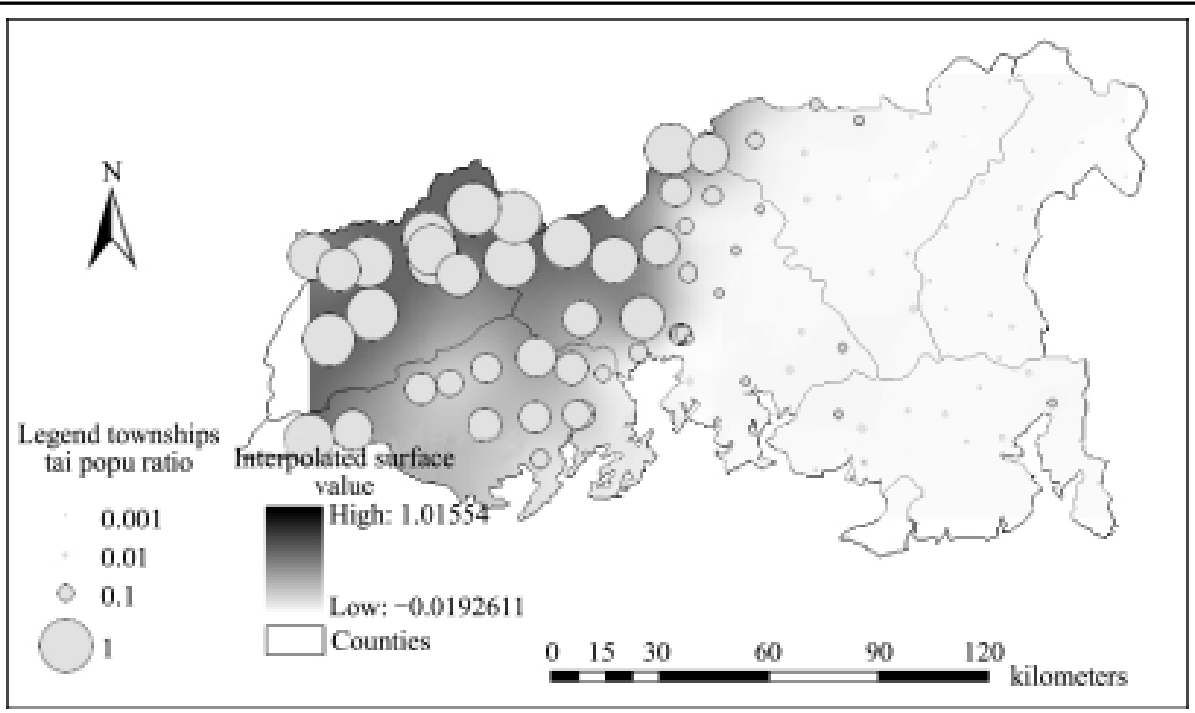

Figure 7. Trend surface modeling of Tai population ratio in Qinzhou (2000)

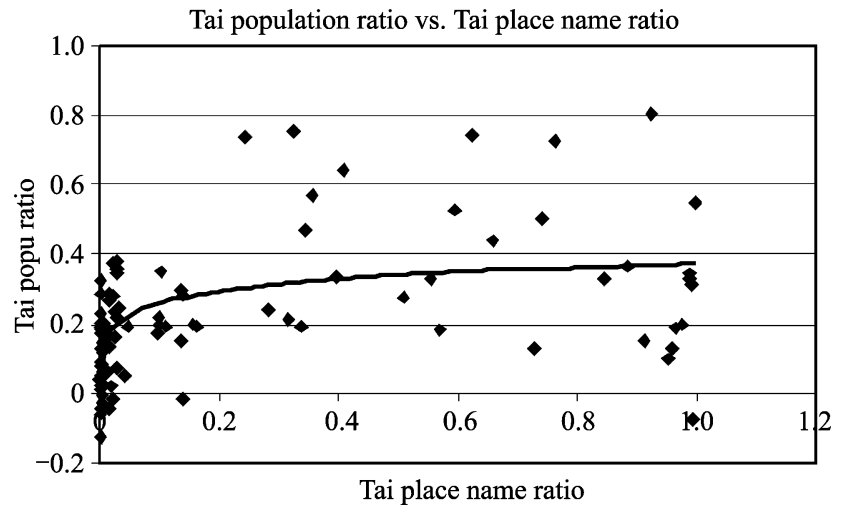

Figure 8. Tai population ratio(2000) vs. Tai place name ratio (1979)

related to the settlement and migration patterns of different ethnic groups. In a recent paper, Hartmann (2003) discusses some of the earliest points where Tai were most likely displaced by the arrivals of Han from the north. A recent GIS study by Luo et al. (2004) on the Kra (cousins of the Tai) shows a northsouth pattern of distribution and migration pattern along waterways and across present national boundaries. The historical interaction between the Tai-speaking minorities and Han Chinese were promoted by road networks and proximity to major political and trade centers (Luo, et al., 2005).

In summary, physical environments including topography, proximity to major transport and trade routes and Han Chinese's migration history may affect Tai's settlement and thus the presence of Tai place names. These factors can be measured as elevation and distances and obtained by GIS overlay operations. A logit regression model can then be constructed to explain whether a place name is Tai or non-Tai. In the logit model, the dependent variable is a dummy variable (i.e., 1 for Tai place name and 0 for non-Tai place name) and the above spatial measures are used as independent (explanatory) variables. In the following illustrative example, we identify three explanatory variables to explain the place names.

First, we speculate that elevation may affect the Tai settlement pattern. As Han pushed south, Tai were driven towards more marginal land (e.g., mountainous areas and thus possibly higher altitudes). Second, the main path for the southward migration of Han was the Meiling Pass (see Figure 1 for the location) that penetrated the barrier of Lingnan Mountain. So it is hypothesized that there was less influence of Han and thus more presence of Tai place names in areas farther away from the Meiling Pass. Third, if the influence of Han followed the major transport or trade routes, it is expected that areas farther away from the routes would experience less sinification and thus have more Tai place names.

The logit regression is obtained by maximum likelihood (ML) estimation. The overall chi-square for likelihood ratio is 32.69 (significant at 0.0001 with 3 degrees of freedom), and the predicted logit is

$$
\begin{array}{ccc}
\mathrm{L}=-9.942-1.0256 \mathrm{ELEV}+ & 0.0124 \mathrm{D} \_\mathrm{ML}+0.008 \mathrm{D} \_ \text {ROUT } \\
(35.09) & (0.52) & (26.29)
\end{array}
$$

where ELEV, D_ML and D_ROUT represent elevation, distance from the Meiling Pass and distance from major transport routes respectively, with the corresponding chi-square values in the parentheses. The dependent variable $\mathrm{L}$ is the logit of a place name being Tai. For example, for a place with ELEV $=0.2 \mathrm{~km}$, D_ML $=750 \mathrm{~km}$ and D_ROUT $=30 \mathrm{~km}$, the predicted L is -0 . 6071 according to the regression model, and therefore the probability of being a Tai place name is $1 /\left(1+\mathrm{e}^{-(-0.6071)}\right)=0.353$. The chi-square values in the parentheses indicate that only the distance from Meiling Pass is statistically significant, and the positive coefficient shows that a place farther from the Meiling Pass is more likely to be a Tai place name. The distance from major transportation routes has the expected sign (positive) but not statistically significant. Elevation may not be a good measure for capturing physical environments and 
is not statistically significant either. Efforts are under the way to define various quantitative morphometric parameters to characterize and differentiate watershed basins that provide favorable environment for Tai settlements. Our future work will include possible explanations by ethnolinguistic features such as dialect differences and language contact, and historical events such as war, forced relocations, assimilation to majority practices, and, not insignificantly, the barrier to Han settlement in areas where malaria was endemic and killed the newcomers by the thousands (Bello, 2005).

\section{SUMMARY AND DISCUSSION}

The sinification of ethnic minorities, such as the Tai, has been a long and ongoing historical process in China. One indication of historical change is reflected in place names over time. Many older Tai names can be recognized because they are named after geographical or other physical features in Tai, such as "rice field”, "village”, "mouth of a river", "mountain”, "basin”, etc. On the other hand, many other older Tai place names have been obliterated or modified in the process of sinification. The objective of a larger project is to reconstruct the linguistic and historical past settlements of the Tai from place names. This research is part of the larger project covering the entire Tai language domain including southern China and Southeast Asia dated back over 1000 years ago. This exploratory research uses a small study area (i.e., Qingzhou Prefecture in Guangxi Autonomous Region in southern China) covering one year (1979) to test some of the analytical methods that will be used in the larger project.

In particular, this study shows how modern GIS and spatial analysis techniques can benefit researchers in historicallinguistic-cultural studies. The classification of place names in the study area is first coded in GIS as a binary variable identifying whether a place name is Tai $(=1)$ or non-Tai $(=0)$. A common spatial smoothing technique, i.e., the floating catchment area (FCA) method, is then used to compute a Tai place ratio within a radius of each place to measure the degree of Tai place concentration. To better visualize the spatial variation of Tai place name concentration, a spatial interpolation method, i.e., trend surface modeling, uses Tai place ratios known at the places to estimate unknown Tai place ratios at any locations, and generates a continuous surface for the whole study area. While spatial smoothing and trend surface modeling are useful for mapping the Tai place names, both methods are merely descriptive. Spatial cluster analysis detects whether the occurrences of Tai place names in some areas are significantly more frequent than other areas. The correlation analysis for the study area validates the assumption that the distribution of Tai population is generally consistent with that of Tai place names. Finally, a logistic regression model is constructed to examine how Tai place names may be related to physical environments, proximity to major transportation routes and the major southward migration entry point of Han Chinese.

\section{REFERENCES}

[1] Bailey T. C., A. C. Gatrell, 1995, Interactive Spatial Data Analysis. Harlow, England: Longman Scientific \& Technical.

[2] Bello D. A., 2005, To Go Where No Han Could Go for Long: Malaria and the Qing Construction of Ethnic Administrative Space in Frontier Yunnan. Modern China, 31: 3: 283-317.

[3] Deepadung, Sujaritlak, 2003, Toponyms in the Western Region of Thailand. In Manusya, Journal of the Humanities. Bangkok: Chulalongkorn University, pp. 31-65.

[4] Diamond, Jared, 1997, Guns, Germs, and Steel: The Fates of Human Societies. New York: W.W. Norton \& Company.

[5] Fotheringham A. S., C. Brunsdon, M. Charlton, 2000, Quantitative Geography: Perspectives on Spatial Data Analysis. London: Sage.

[6] Hartmann J. F., 1998, A Linguistic Geography and History of Tai Meuang-Fai (Ditch-Dike) Techno-Culture. Journal of Language and Linguistics, 16: 68-100.

[7] Hartmann J. F., 2003, The Physical Landscape of GuangxiGuangdong(Lingnan) and Early Points of Entry by the Han. Paper presented at the Midwest Conference on Asian Affairs. Illinois State University, Normal, Illinois, October 10-12.

[8] Husson O., et al, 2001, The Effects of Micro-elevation, Soil, and Water on Rice Growth and Yield in Acid Sulphate Soils in the Plain of Reeds, Vietnam. Tropical Agriculture 78, 8.

[9] Kaluzyñska, Irena, 2002, Contemporary Chinese Place Names: Names of Administrative Divisions at County and City Levels. Bern: Peter Lang.

[10]Kullavanijaya, Pranee, Amara Prasithrathsint, Suvanna Kriengkraipetch, 1996, Collection of papers on the relationship between the Zhuang and the Thai. Bangkok: Chulalongkorn University.

[11] Luo W., J. F. Hartmann, E. DeBord, 2004, An Overview and GIS Exploration of the Physical Geography of Southern China with Respect to the Population Distribution of the Kra and Tai Languages (working paper).

[12] Luo W., J. F. Hartmann, J. Li, V. Sysamouth, 2000, GIS Mapping and Analysis of Tai Linguistic and Settlement Pattern of Southern China. Geographic Information Sciences 6: 129-136.

[13] Luo W., J. F. Hartmann, P. Huang, J. Liu, V. Sysamouth, 2005, Geographic Patterns of Zhuang [Tai] Kinship Terms in Guangxi and Border Areas in Southern China: A GIS Analysis of Language and Culture Change. Submitted to Professional Geographer.

[14] O’Connor, Richard A., 2000, Who are the Tai? A Discourse of Place, Activity, and Person. In Dynamics of Ethnic Cultures Across National Boundaries in Southwestern China and Mainland Southeast Asia: Relations Societies and Languages (Ed. Yukio Hayashi and Guangyuan Yang. Chiangmai: Lanna Cultural Center, Rajabhat Institute, 35-50.

[15] Stanley D. J., Z. Chen, 1996, Neolithic Settlement Distributions as a Function of Sea Level-Controlled Topography in the Yangtze delta, China. Geology 24, 1083-1086.

[16] Wu Wenyi, 1988, Rice Planting Culture as Reflected in the Place Names of the Guizhou Bouyei Language. In Guizhou Altiplano Bouyei Language Place Names and Bouyei Ethnic Group Paddy Working Culture: Guizhou Ethnic Group Study 2, 589-599.

[17] Yunnan Placename Editorial Committee, 1997, Yunnan Provincial Gazetteer, Volume 63: Place Names (in Chinese 云南省志, 卷 63, 地名志).

[18] Zhuang, Shengzhen, et al.(Eds), 1988, Guangjsih Vahcuengh Diegmengz Senjciz (in Chinese). Guangxi, China: Guangxi Minzu Press. 